\title{
Teamwork Management of College Students' Association-Taking China West Normal University as an Example
}

\author{
Yong Tang ${ }^{1, a,{ }^{*}}$ \\ ${ }^{1}$ China West Normal University, Sichuan, Nangchong, 637002 \\ a34412402@qq.com \\ ${ }^{*}$ Corresponding author
}

Keywords: Student community, Team management.

\begin{abstract}
In recent years, teamwork is the management mode which is valued most in management field. On the one hand, implementing the teamwork management in students organizations is to promote the efficient operation of the students' association, and to play the educational function of Students Association preferably; at the same time, it can cultivate team-work spirit of the students and improve the students' comprehensive quality and also promote the students' ability of innovation and their comprehensive development better. Taking China West Normal University as an example, this article studies the teamwork management of college students' association.

In 1994, Stephen Robbins, the professor of science authority in American San Diego university organizational behavior management, was the first one who put forward the concept of "team", which is a formal group formed by some collaborative individuals to achieve a certain goal. In the next ten years, the concept of team management swept the whole world. It is even considered that in the near future the bureaucracy that ruled the entire world over the past few years will disappear, but will be replaced by the operating mode based on teamwork. Some reports show that both the enterprise and the public sector, the team work has clearly improved the efficiency, performance, and even improved the moral level of the members. The goal of university education is to cultivate morally, intellectually, and physically developed talents who are good at social adaption. It contributes to achieving the goal of talents cultivation among college students by strengthening the cultivation of team spirit to implant team management idea into students' mind. This paper studies the way of transplanting team management model in the process of students' organizations for training management in China West Normal University, and discusses the process of implementation of the team management in university personnel training.
\end{abstract}

\section{The issue-The defect of the students association's traditional management}

This paper refers to the college students' community, which refers to the organization formed by some students who voluntarily become the members of the association to achieve the common goals, in accordance with their charter to carry out the activities of the non-profit of students. Students' associations often have their own unique interests and activity patterns. Generally speaking, student associations have clear administrative departments and advisers. There are two modes to follow for the management of community, one is that communities can develop only for macro beam about guidance; the second is strictly to implement a hierarchical management according to their formal organizing cadres.

In the first mode, the organization of the students is looser. The quality of the activity is not so good; the training effect of the students' comprehensive ability is limited. Because of the high mobility of the members of the community, it is necessary to recruit a large number of new members each year. Due to many new members of the team and the weak ability of work, most members often in a semester have been eliminated, and finally the minorities of them are able to win to become the backbone of the community. Therefore only a handful of them can get opportunity to improve them. It is unable to realize the more members of the all-round development. Because of the high mobility, the members lack communication between each other, and the members of the community feelings are not deep, and community cohesion is not strong. It is 
difficult to train the interpersonal skills, social adaptation ability, team cooperation ability of the members of the community, and realize the student's development in an all-round way, but to some extent will strengthen the students' cognitive adverse of lazy, irresponsible and flouting the rules.

In the second model, the essential characteristics of the Student Association has been changed, which is no longer the free groups for hobbies, but the students' hobbies are often subject to more stringent restrictions. The members lack the development goals that are closely related to their own interests, but must keep the organization in line with the organization. In this mode of management, members of the community are more to obey the teacher's arrangement. Community members cannot make full use of their autonomy and their creativity; it is easier to lose vigor and vitality for our society

\section{Team management-The practice of the new pattern of student community organization}

There is no doubt that the traditional organization management pattern has shortages. China West Normal University has implemented the teamwork management in a number of student communities, which has achieved remarkable results. The so-called team management is to use the special skills of the members and encourage them to participate in the cooperation to contribute to the development of the organization, and also the cooperation management (Collaborative Management), or as a participatory management (Participative Management). In this paper, the author applies team management mode to the application of Electronic Association, which can promote the construction of community effectively, and also promotes the cultivation of students' talents. Applied Electronics Association is composed of the school of Applied Electronic Technology Major Students and electronic enthusiasts, through the team management, to create a efficient, vitality of professional societies of college students and become an important stage of electronic technology and design students.

\section{Using the teamwork management to form a good student community}

The construction of team ideas and goals. Mallow, a psychologist, said: "the salient features of the outstanding team are the common vision and purpose." Therefore, the first thing for the establishment of the team is to establish a common vision and purpose. The students' community has the characteristics of randomness and loose, as each member of the complex ideas, they have different needs, different motivation, different values, and different ability level. The key factor of building the core team of students' community is to clear the forward and core idea of the team, and to unify all the people to the long-term and core ideas. In the application of electronic association management. Firstly, the author clarifies the team's core objectives, that is, to become school the best professional student organizations, has become an important platform for electronic professional students the skills training to expand, become an important training base for the talent of electronic design contest, each member have become independently of the electronic information engineering talents; to make clear the concept of team, that is "iron discipline, home warm". Activities like the member recruitment, training, daily management, activity organization, competition planning a series of process of strengthening and propaganda, enable each member to understand the team goals and mission, and individual roles and responsibilities. At the same time, each member has to set the development target of individuals in the team according to their own actual situation.

The building of a permanent team. Permanent team, often treated as family group, is composed of members of the management personnel and excellent subordinates of relatively fixed team. College students' community members do not have to pursue the perfect, but the first thing is to form a good permanent team. A good student society is not a mob, but from the point of view of a team, are the members of the reasonable selection and collocation. Electronic Association in member selection process, in addition to students' interest, pays more attention to members of their own basic quality, which requires actively sought the ideological and political progress, strong sense of responsibility, the spirit of pioneering and innovative, willing to sacrifice; study hard, 
excellent performance, can deal with the relationship between social work and learning. The most important is that pay attention to the choice of team consciousness, willing to work with others to enter the community. At the same time, also pay attention to complementary skills, complementary style, choose different skills and skills, different style of the students to enter the team.

The formation of the project team. In the construction of the permanent team, at the same time, to solve a specific problem, you can also form a project team, or group special. Every club can join a different team. In the application of Electronic Association member of the training process, according to the need of training by members of the community composition in coordination with team, speaker team and the test team. Coordination team is responsible for the arrangement and coordinates the work of the whole training, speaker team responsible for speaker training content, test team to graduation assessment. In the daily management process, set the daily affairs team, the competition planning team, skills training team. Each team member rotates every semester. The organization of the contest activity also carries out team. In China West Normal University 2015 National Electronic Design Contest qualifying process, application electronics association formed publicity team, competition team organization, logistics service team, contact team coordination, motor fielding team, effectively completed the organize the work of the event.

\section{The using of team management to manage student associations}

The management of the whole process of penetration team spirit. The team management of student community organization, in addition to the formation of team, but also pays attention to the long-term operation of team management mode. The process of the application of Electronic Association recruited the training, daily management, activity organization, competition organization completely according to team mode, the full penetration team spirit. In the member recruitment process, interview used team interview mode. Interview content tightly around the design team, during the interview, candidates are also involved in each other's score, the score results with the interviewing team are composed of jury of results together as members of the recruitment eventually basis. In the course of training, the teamwork management team to design the training program and the selection of training methods. Community members own also served as a training speaker, mutual exchange of each other's expertise and talent, on the one hand which is to improve the training of skills, but also improve the speaker of its expression ability, and promote common progress.

The cultivation of the core member and notice to the differences of each member development. It is important to choose good ability and responsible members as a member of the core, and to focus on cultivating core members working ability and organization ability, communication ability, and to give a wider range of authorization and clearer division of responsibilities for core members. In the strict requirements of the core members, it is necessary to give them more care, guidance and help. At the same time, we have to admit that the diversity and difference of community members. Different ideas should be encouraged, and teams need to develop a culture of mutual encouragement and support among the members. To protect each member of the positive views and different ideas is to develop the interests of the maximum degree among the individuals.

The guidance of the work, the most important is the target, strengthen supervision. After all, the students' community is different from the enterprise team, the work ability; ways of doing things are still room for improvement and the need to improve. To strengthen the guidance of the team to the team, according to the development of the team, to develop different practical goals. The formation of the team is divided into different periods, that is, according to the different team maturity, can be divided into the formation period, the period of aggregation, the intensification of the harvest period. Different management focus should be used in different periods, and different countermeasures are applied. To guide the teacher to clearly take the actual state of the team, take different management strategies. In the course of the work, to strengthen the supervision of the team, and timely correction of the deviation and team problems in the work. 
Strengthening team norms and incentives. "Nothing can be accomplished without norms or standards". Lack of norms in the organization will cause a variety of problems, not only will cause confusion, confusion, will also cause speculation, distrust. According to the actual situation, the student association to establish reasonable and is conducive to team's standard, including standardized management, duty procedure specification, specification, standardized assessment, incentive regulation; to strengthen the implementation of the standard, make the team member identity specification, compliance, the full implementation of the team construction. To strengthen the work performance management, the establishment of scientific and reasonable, fair and fair evaluation and assessment system. The cadre team and individual of regular and irregular evaluation, evaluation results and timely feedback, allow students to make mistakes and urge students to improve their work performance, work at the same time quantitative assessment. To improve the incentive measures, the formation of Student Association Awards linked with the evaluation results of the incentive mode. To follow the humanization of the student oriented motivation, always pay attention to the ideological and life of the students, life, learning, the best cooperative team, the most hardworking community members to give recognition and reward.

\section{The effect and experience of team management for students' community management}

Student associations in the implementation of group management, better in the cultivation of the students' consciousness of team, better to promote the work of development, improve the socialization of the students, which all are to meet the social requirements for new talent.

\section{The effective realization of national education policy}

The basic policy of the new period of our country is taking the students first, and realizing the full development of the students. The team is based on the individual's interest and achievements, but does not require the team members to sacrifice themselves. On the contrary, showing personality and expertise to ensure the performance of the members has completed the mission objectives. In student associations to achieve team management can truly realize people-oriented, so that every member of the team have received attention, and the strengths of each member are displayed, and their defect can be remedied. Every member has the sense of achievement, which effectively promotes the implementation of the national education needle.

\section{The promotion of the healthy development of the community}

The core of the team is the cooperation, and the highest level is the solidarity between the members of the whole. And also the core reflects the unity of the individual interests and the overall interests, and thus ensues the efficient operation of the organization. In addition to importance of the core of the team, all members shared decision-making power and shared responsibility. In addition to common goals in the team, but also all members can give their own goals. Through team management, all members through a team effort finds their own positions and their own value and they have a strong sense of identity to the club, sense of belonging, sense of responsibility and sense of ownership, and also they are willing to pay for energy and effort. It is important to strengthen the cohesion of the students' community and their fighting energy, so as to play each member of the greatest potential, better promote the development of community.

\section{The promotion of the comprehensive development of community members}

The needs of today's society are talents. Not only does the society need a solid foundation of knowledge, practical skills, excellent organization and coordination ability, but also a good sense of teamwork, unique and innovative spirit, tenacious spirit of hard-working. Now the students mostly live in the one-child family, with a strong sense of self central and personal superiority, the lack of awareness and ability to cooperate with others. Practice has proved that through the implementation of team management, through cooperation with other members of the team, communication, social members of the quality have been greatly improved. 


\section{Promoting the quality of students cultivated by university}

Team management makes students associations form a good sense of community and build a positive spiritual outlook. We can expose the team awareness to other student organizations and the majority of students, through promoting excellent performance of the students associations, and exerting association members' demonstration effect. Thus, teamwork awareness can be formed among all the college students and the enhancement of students' coordination ability and socialization competence can be facilitated. It has positive impact on facilitating the building of school spirit and climate for learning, and improving the quality of talent cultivation.

\section{Reference}

[1] Mingxian Zhao, Min Lu, The training mode of team work and its performance evaluation of students in Colleges and universities [J]. Agricultural Science and Technology Management, 2005, (05).

[2] Hao Cai. On the cultivation of college students team spirit in the new period [J]. Journal of Changchun University of Science and Technology (High Education Edition), 2008, (01).

[3] Ping Wei. The practice and thinking of college students team spirit cultivation [J]. Economist, 2007, (08). 